\title{
REVIEW | Soundtracks of Asian America: Navigating Race through Musical Performance
}

\author{
Grace Wang
}

Durham and London: Duke University Press, 2015

ISBN: 9780822357811 (PB)

\section{Timothy Laurie \\ University of Technology Sydney \\ timothy.laurie@uts.edu.au}

Stereotypes like to travel. Like Frankenstein's monster, they gain piecemeal limbs by trampling across disparate cultural domains, from television spoofs to fashion labels to schoolyard jokes. Stereotypes cannot easily be defeated by corrective information about the concrete diversity of persons, because they travel through lines of social desire - wanting to be or to not be something; wanting to mark strong differences or no differences; wanting to create distance from others or to affirm unity through the powers of exclusion. Desires for stereotypes can therefore manifest through varying modalities of mimicry, longing, disgust, nostalgia, and exhaustion, and even disavowals of stereotypes can become new routes through which stereotypes travel.

Soundtracks of Asian America: Navigating Race Through Musical Performance is not exclusively about stereotypes though. Grace Wang addresses problems around racial identification alongside questions concerning the democratizing effects (or not) of YouTube, class mobility at a classical hothouse in New York, and trans-Pacific mobility for Leehom Wang, an American Born Chinese (ABC) performer highly successful in East Asia. Nevertheless, each example cycles back to the book's central query concerning social identities in a racialized field: "how do Asian Americans mobilize the multiple meanings contained in music to 
engage with, critique, and, at times, profit from their racial positioning in national and transnational spaces?" (3). The four chapters hold together lively arguments about Asian American performers building musical careers and communities, and seek to navigate racialized stereotypes attached to Asian identities in North America - the "Tiger Mother" (28-63), the "Asian girl violinist" (77, 89), the "cookie cutter" performer (83), and so on. Outlining a broad conundrum faced by Asian and Asian American musicians (67), Wang unearths the following cultural logic of race and sound:

Their Asianness, while for the most part visually inescapable, must remain sonically invisible. And yet, playing at the "universal" level can also make Asian American classical musicians suspect, subject to such backhanded compliments as, despite their Asian background, their music making sounds innate. (68)

Such a challenge finds a loose correlate among Asian American YouTube performers and fans, who exhibit shared desires to see someone like themselves achieve online musical celebrity (125), while remaining attached to "post-racial" ideals of "colour-blind listening" (134). In response to the racism of North American music industries, Wang cites examples of Asian Americans engaging in online community building practices (118), critically re-appropriating of racist vocabularies (170), and carefully negotiating the transnational commerce in "Asian chic" (172).

The key strength here lies in Wang's careful handling of social orientations toward and investments in slippery cultural identities. The introductory criticisms directed toward racial essentialisms are balanced by addressing the everyday language used by artists (and artists' parents) to make sense of complex cultural and musical histories attending national and regional designators ("Chinese", "East Asian", "Asian" and so on). The opening chapter examines Asian American parents of classical music performers, focusing both on the circulation of clichés about Chinese and Korean parenting styles, and on parents' own motivations when sending children to elite schools. Chapter 2 examines personal accounts from Asian American performers themselves, with a strong focus on cultural authenticity and the construction of "Europeanness" in relation to classical performance, as well as some nuanced observations about registers of racism in classical music industries. Semi-professional YouTube celebrities are the focus of the third chapter, with eclectic contributions from performers and fans immersed in convivial online Asian American communities. The fourth chapter confronts the transnational audio-visual extravaganza that is Leehom Wang. The successes of Asian American performers in East Asia are noted in previous works on Chinese pop and rock (see, for example, De Kloet 2010: 54-60), but are rarely analysed from the viewpoint of the transnational cultural politics surrounding $A B C$ identities.

Soundtracks of Asian America showcases a rich diversity of young Asian American voices while sustaining its opening critique of racialized stereotypes. This is not always an easy balance. In response to the negative stereotyping of Asian Americans' classical performance techniques, Wang offers the following interview fragment: 
Observing that "the majority of non-Asians believe" these stereotypes, [interviewee] Eric added: "I tend to believe them too ... But I think it's not a fault of their own; it's a fault of their training". On the one hand, he disassociates himself from the foreignness of Asians as a way to cope with the racism inherent in the stereotype, a strategy that tellingly leaves the racial logic of these stereotypes intact. On the other hand, Eric rearticulates them less as inherited traits than as matters of pedagogy. (80)

Wang also quotes a performer who suggests that classical pedagogies in South Korea may differ from North American methods. The issue may not simply be that stereotypes introduce illusory differences in contexts where everyone would actually sound the same (although this can happen, too). Rather, stereotyping can narrow the frames through which a plethora of differences come to be understood and given cultural meanings, while imposing false uniformities and equivalences; for example, South Korean performers may broadly have different training to Korean Americans. This distinction comes further to the fore when Wang interviews parents of performers.

Asian American performers' parents do not appear concerned that they conform to stereotypes, as popularized by Amy Chua's The Battle Hymn of a Tiger Mother (2011), or to subsequent media narratives about "authoritarian" Asian parents (186-192). Negative social perceptions are gestured to only in passing; as one interviewee suggests, "Whatever is good for [the children], we like to provide for them as much as we can even if we waste a lot of time, a lot of driving. American parents, they think Asian parents are crazy" (50). Here Wang reaches for a summary argument that warrants careful consideration:

[It] is worth questioning whether Asian parents' lack of cultural fluency and their outsider status in the United States lead them to misapprehend the amount of cultural capital that can be accrued through classical music training. It may be that the increasing participation of Asian Americans in classical music has merely re-entrenched prevailing stereotypes about Asian parents as excessively pushy, competitive, status-driven, and overbearing and Asian Americans as model minority subjects who are culturally distinct from their normative and allegedly more balanced American counterparts. (62)

This is a sociologically elegant argument. As those without cultural capital seek to acquire it, the value of the capital goes down in the eyes of those who have plenty. But is this how cultural capital works? To whom does it matter, for example, that "parents' intense involvement in Western classical music training has failed to grant them the image of refinement and erudition they seek to display" (190)? It may be that classical music attracts status within a particular community network, even if this community is derided or satirized elsewhere. In Wang's study, the Asian American parents interviewed appear oriented toward their immediate peers in different Asian American communities (48-49), rather than toward North American news media. Of course, the propagation of cultural stereotypes about Asian American parents can produce serious problems for young Asian American performers, and the latter may encounter racisms unanticipated by their parents, as noted in scholarship on migration and generationalism (see, for example, Pyke and Dang 2003). But it remains salient 
that Asian American parents may have correctly apprehended the logics of their social worlds, the approval of North American news media notwithstanding.

Generational differences implicitly frame Wang's argument as online music communities and transnational music genres - and in particular, Cantopop, Mandopop, and K-Pop - have created new articulations between nation-States and cultural identities, including new forms of participation in mobile youth cultures throughout the East Asian region (see Chow and De Kloet 2013; Yu and Yue 2008). The focus here is on notions of the "Asian" in "Asian American", but it may be that the "American", too, will require further interrogation in future work, especially as East Asian pop becomes more successful in the United States. Nevertheless, this study provides a subtle account of local contexts, especially regarding music colleges, that many sweeping accounts of global media flows are unable to deliver.

Each chapter is much like the YouTube fan communities that Wang feels are "personal, immediate, and even private" (124), even when tackling broad patterns around institutional racisms. Wang succeeds in layering multiple registers of experience surrounding racialized stereotyping, such as familiarity, aversion, and flight, while remaining sensitive to the personal desires and idiosyncrasies of musical performers. In following stereotypes across different social domains, Wang opens up some broader questions about Asian American musical geographies and practices of community formation. Future research on these issues will greatly profit from close readings of Soundtracks of Asian America.

\section{References}

Chow, Y.F., and De Kloet, J. 2013. Sonic Multiplicities: Hong Kong Pop and the Global Circulation of Sound and Image. Bristol: Intellect Books.

Pyke, K. and Dang, T. 2003. "Fob" and "Whitewashed": Identity and Internalized Racism among Second Generation Asian Americans. Qualitative Sociology 26(2): 147-172.

Yu, H. and Yue, A. 200. China's Super Girl: Mobile Youth Cultures and New Sexualities. In U.M. Rodrigues and B. Smaill Eds. Youth, Media and Culture in the Asia Pacific Region. Newcastle: Cambridge Scholars Publishing: 117-134. 